\title{
Profit Sharing and Innovation
}

Kris Aerts and Kornelius Kraft

DEPARTMENT OF MANAGERIAL ECONOMICS, STRATEGY AND INNOVATION (MSI) 


\title{
Profit-sharing and innovation
}

\author{
Kris Aerts* and Kornelius Kraft* * \\ ${ }^{*}$ K.U.Leuven R\&D and K.U.Leuven, Dept. of Managerial Economics, Strategy and Innovation, Belgium \\ ** Technical University of Dortmund, IZA and ZEW, Germany
}

October 2008

\begin{abstract}
We investigate the effect of profit-sharing on product and process innovation. Profit-sharing is a credible commitment of the companies to let the employees participate in any efficiency gain. Resistance against technical progress becomes less plausible. Moreover, employees are stimulated to share their specific information advantage on possibilities to optimize the production process and products with the management. Using survey data on German companies with and without profit-sharing in a conditional difference-in-differences framework, we test our hypothesis by comparing measures of innovativeness. Firms with a share system are more successful with respect to both product and process innovation.
\end{abstract}

Keywords: profit-sharing, product innovation, process innovation, non-parametric matching, conditional difference-in-differences

JEL-Classification: M52, J33, C14, O32

Kris Aerts

Address: $\quad$ K.U.Leuven Research \& Development

Minderbroedersstraat 8A P.B. 5105

BE-3000 Leuven

BELGIUM

Phone: $\quad+32(0) 16320649$

Fax: $\quad+32(0) 16326515$

E-mail: $\quad$ kris.aerts@lrd.kuleuven.be
Kornelius Kraft

University of Dortmund

Dept. of Economics

Vogelpothsweg 87

D-44227 Dortmund

GERMANY

+492317553152

kornelius.kraft@uni-dortmund.de 


\section{Introduction}

Knowledge has become a fundamental economic asset (see e.g. Romer, 1990) and determines companies' competitive strength (Schumpeter, 1942). On the one hand, knowledge creation is a time and money consuming process, with an uncertain outcome (Dasgupta and Maskin, 1987). Optimal staff motivation is to the benefit of expected success. On the other hand, knowledge spreads relatively quickly into the public domain once it has been created, allowing other companies to take advantage of the originating company's investments. Mansfield (1985) showed that a significant share of knowledge leaks out through employees. Therefore, in knowledge creating companies, it is vital to attract valuable employees and curtail the staff turnover and additionally, to motivate this highly qualified workforce. One important aspect is employee remuneration. A vast body of research is devoted to investigating optimal remuneration systems and it appears that monetary as well as non-pecuniary incentives matter (see e.g. Coombs and Gomez-Mejia, 1991), jointly optimized in a stimulating work environment with an attractive remuneration system. In this paper, we zoom in on one specific remuneration system, namely profit ${ }^{1}$ sharing: employees share in the profit of a company, through the receipt of financial rewards, depending on the company's performance. Often, this financial incentive is disbursed as a supplement to the fixed base wage (see Kraft and Ugarković, 2007; Bhargava and Jenkinson, 1995 as well as Wadhwani and Wall, 1990).

The direct aim of companies introducing profit-sharing in their remuneration policy is to stimulate staff performance. As profit maximization becomes a win-win strategy to all parties involved, i.e. both the employees and the firm owners, their mutual interests become aligned. If the incentive system works in an efficient way and if employees behave rationally, they increase their efforts, which should subsequently raise the company's performance. Since a considerable time, profit-sharing has been the subject of many empirical studies (see e.g. Pérotin and Robinson, 2002 as well as Strotmann, 2002, for elaborate surveys of this literature stream). The direct link between profit-sharing and output explains why traditionally productivity has by far been the most often investigated issue in this research domain. Less frequently investigated topics are the effects on profitability and wages. The latter variable is

\footnotetext{
${ }^{1}$ Also 'capital sharing' exists, a system in which employees hold shares of the company and in this sense, become co-owners of the company. This issue lies beyond the framework of this paper, though.
} 
investigated as Weitzman (1983) suggested using profit-sharing as an alternative, instead of a supplement to the going wage rate.

Scholars typically find positive to neutral impacts of profit-sharing on a firm's output. However, productivity measures only show part of the picture, as they merely reflect the final impact, without illuminating possible reasons explaining this productivity increase. An efficient incentive system is expected to affect workers' performance, but may additionally strengthen a company's innovative capabilities, as theoretical arguments predict that potential resistance against innovative activity can be offset and what is even more, employees may actively cultivate the company's innovative capabilities.

In this paper, we introduce measures of technological progress in an attempt to unravel how the introduction of profit-sharing may interact with firm performance through the realisation of both product and process innovations. This area has remained by and large unexplored until now. We employ an extensive dataset on German firms. In order to eliminate possible selectivity effects, we apply conditional difference-in-differences methods. In the second section, we briefly summarise the history of research on profit-sharing and advance some theoretical considerations. The third section entails the strategy we follow in the empirical part, which is subsequently presented in two sections, covering the data description and the estimation results. The last section concludes with a summary of our findings, some limitations of our research set-up and lines for further research.

\section{Literature summary and theoretical arguments}

The literature on profit-sharing can be categorized into two substreams. The first substream, which is especially supported by the European Community (see the so-called Pepper reports: Commission of the European Communities, 1991 and 1996, and Lowitzsch, 2006), tries to provide a framework for international comparisons and to quantify the prevalence of profit-sharing in Europe and the US. However, definition problems and internationally different legislation schemes seriously complicate these studies and imply strong limitations with respect to their comparability.

The second substream of literature investigates the potential impact of profit-sharing on various company characteristics. As mentioned before, the traditionally most investigated variable in this domain is productivity. The interested reader is referred to FitzRoy and Kraft (1987) as one of the first studies, Doucouliagos (1995) for a meta-analysis and to Pérotin and 
Robinson (2002) as well as Strotmann (2002) for elaborate surveys of the extensive literature. Overall, the conclusions tend to confirm small but positive productivity increases as a result of profit-sharing. Other variables which are studied in relationship with the existence of profit-sharing are wages and labour demand (see Pérotin and Robinson, 2002), as well as profitability (Kraft and Ugarković, 2007). An important issue, which is nevertheless often ignored, is the fact that different selection mechanisms may play a part when studying profitsharing and its impact. This may seriously distort evaluation exercises and undermines the validity of the results. In the methodological section, we will extensively come back to this issue of selectivity.

To the best of our knowledge, no studies exist on the impact of profit-sharing on the innovative performance of companies. However, in the subsequent paragraphs we will advance theoretical arguments and predict a potential positive impact of this specific remuneration system on the company's innovation process.

Although a high-quality workforce is expected to produce highly valuable $R \& D$ and innovative output, there are two main motives why employees may hamper innovative activity. First, employees are expected to dislike technological change if its introduction implies re-training, alternative work organizations and adaption costs, in addition to potential dismissals. Training will most likely be firm-specific and thus the risk for the workers increases, which may therefore excite opposition against innovative activities within the company. Schaefer (1998) found that these frictions do not necessarily obstruct innovative activity, but nevertheless may seriously slow down or change the innovation process. Zwick (2002) proves that internal resistance against innovation is more likely if it is uncertain whether the employees benefit from the investment. Our second argument as to why employees may negatively affect a company's technological progress and innovative capabilities works more directly. New technologies may enable companies to substitute labour by capital. This in turn may lower the demand for labour and therefore reduce employment and/or wages. As a result, employees may exhibit a substantial scepticism or even negative attitude towards technological progress. In that case, any attempt to modernize the company's technological equipment or to conduct process innovations will be distrusted or even opposed.

Profit-sharing can provide an effective remedy to counter or even upturn these frictions and the potential negative pressure of human capital on R\&D. First, the premium offered through profit-sharing can be regarded as a compensation for the training and subsequent risk. 
Therefore, profit-sharing may moderate employee opposition against technological advancement. Second, profit-sharing may even stimulate the employees' incentives to actively support and contribute to process innovations. As profit-sharing entails an explicit commitment on behalf of the company owners to share part of the profits with the employees, their mutual interests are aligned towards one denominator: profit maximization. Process innovations are expected to increase a company's future profits, so technological progress is to the benefit of both parties. Employees are closely involved in the company's bench level expertise and may therefore possess an information advantage on potential weaknesses and inefficiencies of the technologies in use. Without profit-sharing there is hardly any incentive to disclose this information to the management. However, when employees participate in any profit increase, it is in their self-interest to fully exploit all available information. Hence, if the company employs a profit-sharing system, employees will be less averse towards strengthening the company's technological equipment, and, even more important, they may become a valuable asset in the process of technological progress. In this paper, we therefore advance the hypothesis that profit-sharing fosters process innovation.

Less obvious but possibly also present is an effect of profit-sharing on product innovation. During the production process, employees go through a learning curve: they accumulate knowledge, gain experience and subsequently may come up with ideas to improve a product's quality. If a monetary incentive is coupled to the implementation of any useful suggestion on a product improvement, the likelihood that the employee discloses his ideas obviously increases. Similarly, employees may become aware of potentially interesting additional features of the produced goods. Hence, while it seems unlikely that employees can contribute significantly to the development of totally new products, they may possess a substantial potential to improve existing products to a significant extent. Moreover, some employees closely interact with the company's customers and as a result are well aware of their preferences. They gather information on potential shortcomings of the existing product range as well as the customers' needs and wishes concerning improvements of existing as well as desired features of future products. This valuable knowledge should be transferred to the company's R\&D department, in order to develop products along these lines. If the company succeeds in complying with these requirements, its market success is expected to rise and consequently also its sales of improved or newly developed products. Profit-sharing generates clear incentives to share this information with the management as, in contrast to the traditional wage-based firm, its capitalization is shared with the source of information: the 
employee. In summary, our theoretical arguments predict that introducing profit-sharing has the potential to stimulate both process and product innovation.

\section{Empirical Strategy: the treatment of selectivity}

Although many empirical studies confirm the hypothesis that profit-sharing has a neutral to significantly positive effect on the company's performance, only a surprisingly small minority of firms actually employs this remuneration scheme. The percentage of firms with a profit-sharing system is quite low in the European Union, except in France and the United Kingdom, where financial participation in companies is supported by a legal framework and substantial tax advantages (see Poutsma, 2001, for an extensive description of country differences in the European Union). This seems to indicate that profit-sharing is not a beneficial strategy to all companies, but only to certain firms. Strotmann (2002) denounces the fact that, even after the clear conclusion of FitzRoy and Kraft (1995) that different selectivity mechanisms may play a role in the evaluation of profit-sharing, many studies do not or not sufficiently control for the potential distortion of the results due to these selection biases. This section first clarifies the different arguments supporting expectations about the presence of selectivity. Next, we expound how this problem is solved in our empirical analysis.

A first reason for the rather low ratio of firms employing profit-sharing might originate in firm-specific advantages or disadvantages with respect to different incentive schemes. Companies presumably differ in a number of aspects. For instance, the respective workforces may exhibit different qualification levels. Furthermore, firms may differ in their capability to validate individual performance. Examples are highly structured work processes, e.g. in the extreme belt production, or a team-based production process, where only joint, i.e. not individual, output is observed. In general, smaller firms suffer significantly less from problems in measuring individual employee performance. Other differences may stem from turnover rates, the workforce's cultural and ethical background, industrial relations and many other characteristics. In these circumstances, it is reasonable to believe that firms that are able to capture specific advantages from profit-sharing are likely to introduce this incentive scheme in their remuneration policy, while others show no interest and rather rely on other motivational instruments like tournaments, piece rates or efficiency wages. A second kind of selectivity is driven by worker sorting. Performance oriented and cooperative workers probably prefer working in profit-sharing firms. These workers are presumably more 
productive, irrespective of the presence of a profit-sharing scheme. Moreover, the strong presence of productive and highly skilled employees may increase the productivity of less productive employees through mutual and cooperative learning efforts. In this case, these employee teams differ from teams in the more traditional firms paying fixed wages. This very likely causes differences in any performance measure, including innovativeness. Furthermore, it is quite realistic to assume that employees behave risk-averse and prefer a fixed wage over a variable, performance-related pay. If, for a moment, we set aside the argument raised before, i.e. that profit-sharing usually complements the fixed wage, instead of replacing it, firms paying a flexible wage presumably attract less risk-averse workers. It is not unreasonable to assume that these employees are also more productive. Finally, selectivity in innovation activities may arise. It is quite plausible that highly innovative companies also use efficient incentive systems, simply because they are managed in a better way. Hence, a positive correlation between innovative activity and the use of profit-sharing in the remuneration policy may be due to an unobserved third factor, while actually no causal relation exists.

If selectivity is at work, any empirical methodology neglecting this problem will produce biased results. Using the Heckman estimator, the early study of FitzRoy and Kraft (1995) confirms the strong presence of selectivity effects. Profit-sharing is proved to be endogenous with respect to any outcome measure. Another sophisticated method to deal with selectivity is the non-parametric matching approach, well known in the so-called treatment analysis. Treatment in our case is defined as the use of profit-sharing. This methodology goes back to Roy (1951) and Rubin (1974) and has also been labelled the potential outcome approach. A matching approach re-establishes the conditions of an experiment and compares treated and non-treated observations. The control sample of non-treated companies is selected carefully, to maximize its similarity with the population of treated companies. Every single treated company is related to non-treated units: conditioning on their similarity, a non-treated firm receives a high or low weight, or even is omitted. The determination of the control observation's importance (weight) depends on the selected matching estimator (see Heckman et al., 1997).

Rubin (1974) defines the impact of the treatment as the difference between the likely outcome $\mathrm{Y}$ of an establishment ${ }^{2}$ introducing profit-sharing, $\mathrm{Y}^{1}$, and the counterfactual outcome in the case of non-introduction, $\mathrm{Y}^{0}$, given $\mathrm{D}=1$ :

\footnotetext{
${ }^{2}$ For the sake of readability we omit firm indices in the equations.
} 


$$
\theta=E\left(Y^{1}-Y^{0} \mid D=1\right)=E\left(Y^{1} \mid D=1\right)-E\left(Y^{0} \mid D=1\right)
$$

where $\mathrm{D}$ is a binary assignment indicator determining whether the firm has introduced profitsharing $(D=1)$ or not $(D=0)$. Parameter $\theta$ measures the average treatment effect on the treated firms and determines whether the introduction of profit-sharing has been beneficial to those establishments that introduced this incentive scheme in their remuneration policy.

The fundamental problem in evaluation econometrics arises from the fact that the second term on the right hand side, i.e. the counterfactual outcome $\mathrm{E}\left(\mathrm{Y}^{0} \mid \mathrm{D}=1\right)$, is by definition not observable, since it describes the hypothetical outcome of a firm that actually introduced profit-sharing if it would not have done so. In the absence of selectivity, the following equality:

$$
E\left(Y^{0} \mid D=1\right)=E\left(Y^{0} \mid D=0\right)
$$

would hold and the average outcome of firms without profit-sharing would provide an estimate for $E\left(Y^{0} \mid D=1\right)$. This assumption is valid in an experiment where randomisation of the treatment is given. However, as FitzRoy and Kraft (1995) have shown and as we argued before, it is quite unlikely that profit-sharing and non-profit-sharing firms do not differ with respect to certain characteristics: profit-sharing is endogenous, which introduces a bias in the estimates. The key to solve this evaluation problem is to approximate the counterfactual outcome. We chose to follow the potential outcome (i.e. matching) approach with a time dimension, the so-called conditional difference-in-differences technique. In the following paragraphs we explain the details of this methodology.

Rubin's (1977) conditional independence assumption (CIA) states that the treatment status and the potential outcome are independent for observations exhibiting the same observable set of characteristics $\mathrm{X}$. The validity of the CIA depends on whether all determinants influencing the decision to introduce profit-sharing as well as the potential outcome are known and available for all observations. However, the CIA cannot be tested formally and as a result, the researcher is obliged to rely on the data quality. We believe that the IAB Establishment Panel, which will be described in more detail below, covers a wide array of information, ranging from general information on the establishments to questions on investment, business policy and development to employment-related questions, and therefore serves as a good basis to fulfil this requirement. 
Hence, if sample selection is solely due to observable covariates (a vector X), the CIA applies and the following equation holds:

$$
E\left(Y^{0} \mid D=1, X=x\right)=E\left(Y^{0} \mid D=0, X=x\right) \text {. }
$$

The treatment effect $\theta$ in the matching approach can consequently be estimated by comparing the outcome means of the two groups (Lechner, 1998):

$$
\theta_{M}=E\left(Y^{1} \mid D=1, X=x\right)-E\left(Y^{0} \mid D=0, X=x\right) .
$$

In practice, ensuring the validity of the CIA imposes a major obstacle, since every additional exogenous variable in the vector $\mathrm{X}$ decreases the probability of finding an adequate control group. Rosenbaum and Rubin (1983) proposed a remedy to this dimensionality problem. As an alternative to matching on a large set of covariates, their idea is to match on one single index. This so-called propensity score is estimated with information on the exogenous characteristics X. Rosenbaum and Rubin (1983) show that, if the CIA is fulfilled, one does not need to condition on all covariates contained in $\mathrm{X}$, but only on the propensity score. In our case, this index is estimated as the conditional probability to use profit-sharing, i.e. the probability to share profits with the employees, given a set of individual characteristics of a firm: $\operatorname{pr}(\mathrm{D}=1 \mid \mathrm{X}=\mathrm{x})$. This propensity score is usually estimated in a probit model.

Several matching methods have been proposed in the literature on evaluation econometrics. We employ nearest neighbour matching, which comes down to a pair wise matching as it tries to select the most similar non-treated observation (ideally a "twin") for every treated observation. If the matching procedure was successful, i.e. the establishments that did (treated group) and did not (selected control group) introduce profit-sharing are ex ante equally likely to introduce profit-sharing, equation (3) holds and the causal effect is computed as indicated in equation (4), by comparing the outcome means of the two groups.

The matching approach accounts for the selection bias caused by observable factors. However, as we mentioned before, compliance with the CIA is crucial to obtain reliable estimates: all relevant information should be known and available for all observations. Although we strongly believe that our data at hand are very rich, nonetheless, unobservable factors may be at work and affect the outcome variable. This could seriously bias the results. To correct for this potential selection on unobservables more strongly, the initial matching method can be extended with a time dimension. 
This is exactly what we will do in the empirical part of this paper, as we have a rich two-period panel dataset at our disposal. We present two evaluation methods, assessing the evolution of the outcome $\mathrm{Y}$ after treatment. Matching and difference-in-differences techniques are combined in this method, which is referred to as the conditional difference-indifferences (CDiD) or matched difference-in-differences approach (Heckman et al., 1997).

The general difference-in-differences (DiD) set-up relates the development of an outcome variable of treated observations to the evolution of this outcome variable in a control group of non-treated observations. The before-after change in the outcome of non-treated firms is subtracted from the before-after change in the outcome of the treated firms to obtain the average treatment effect $\theta$ :

$$
\theta_{D i D}=E\left(Y_{t_{1}}^{1}\left|D=1-Y_{t_{0}}^{1}\right| D=1\right)-E\left(Y_{t_{1}}^{0}\left|D=0-Y_{t_{0}}^{0}\right| D=0\right),
$$

where $D$ denotes whether the unit under consideration is treated $(D=1)$ or not $(D=0), Y$ is the outcome variable and $t$ represents the moments in time before $\left(t_{0}\right)$ and after $\left(t_{1}\right)$ the introduction of the measure. The DiD estimator thus measures the excess outcome growth of the treated as compared to the non-treated group, correcting for any macro-economic change over time. If this method is generalized to include additional regressors $\mathrm{X}$, the advantages of the matching and the DiD approach are combined (Blundell and Costa Dias, 2000). This conditional difference-in-differences (CDiD) approach eliminates time-invariant unobserved individual-specific effects as well as common macro trends. Several studies evaluating active labour market policies make use of this estimator (e.g. Kluve et al., 1999; Eichler and Lechner, 2002; Bergemann et al., 2004; Albrecht et al., 2005). The treatment and control group are matched on observable characteristics X such that:

$$
\begin{aligned}
& \left(Y_{t_{1}}^{1} \mid D=0, X=x\right)-\left(Y_{t_{0}}^{1} \mid D=0, X=x\right)= \\
& \left(Y_{t_{1}}^{0} \mid D=0, X=x\right)-\left(Y_{t_{0}}^{0} \mid D=0, X=x\right) .
\end{aligned}
$$

To increase the accurateness and quality of the matching process, two additional activities were carried out. First, for all treated firms a valid counterpart should be found in the non-treated population and every firm should represent a potential profit-sharing company. If the samples of treated and non-treated firms would have no or only little overlap in the exogenous characteristics $\mathrm{X}$, matching is not applicable to obtain consistent estimates. Hence, the so-called common support restriction is imposed and all firms exhibiting extreme values and therefore complicating the matching process are removed. Second, optimal 
matching is obtained when the control sample to select twin companies from, is as large as possible. Therefore, one can opt for matching with replacement. In the current work, we employ the conditional difference-in-differences approach with nearest neighbour propensity score matching and match with replacement. The average treatment effect $\theta$ is calculated as follows:

$$
\begin{gathered}
\theta_{C D i D}=\left(E\left(Y_{t_{1}}^{1} \mid D=1, X=x\right)-E\left(Y_{t_{0}}^{1} \mid D=1, X=x\right)\right)- \\
\left(E\left(Y_{t_{1}}^{0} \mid D=0, X=x\right)-E\left(Y_{t_{0}}^{0} \mid D=0, X=x\right)\right) .
\end{gathered}
$$

We employ two variations of the CDiD method. In the first approach, we match firms which introduced profit-sharing between period $t_{0}$ and $t_{1}$ to firms which have never shared profits, using their respective vectors of exogenous characteristics $X$ in period $t_{0}$. Then, we evaluate how the outcome Y of both groups (treated versus non-treated subjects) has evolved over time, comparing static (assessing $\mathrm{Y}$ in period $\mathrm{t}_{1}$ ) and dynamic (comparing $\mathrm{Y}$ in the periods $t_{0}$ and $t_{1}$ ) variables for the treated and non-treated firms in t-tests on mean equality. We will refer to this technique as CDiD without control variables.

In our second variation on the $\mathrm{CDiD}$ technique, we control for unobserved heterogeneity in a more explicit way and additionally include the evolution in the control variables. The results of the CDiD analysis are presented as OLS and probit models; like in a normal DiD set-up (see also e.g. Aerts and Schmidt, 2008). As Wooldridge (2002) suggests, when the treatment effect is equal for each subject and constant over time, a fixed effects regression model is more appropriate than the random effects model. However, as Halaby (2004) shows, both models are frequently used in treatment analyses, so both estimators are employed and the Hausman test is conducted to test which model is more appropriate. Following Albrecht et al. (2005) we also point out that a disadvantage of employing probit models in this context is that "they do not enable the estimation of the quantitative effect of treatment on the employment outcomes. This effect is non-linear and depends on the unknown fixed effects. This means that we can only make a qualitative evaluation, in the sense that we can only determine the sign and significance of the treatment effect."

\section{The data}

This section describes the data which will be used to empirically investigate the interaction between profit-sharing and innovative performance in Germany. Bellman and 
Möller (2006) quantify profit-sharing in Germany: in 2005 about 9\% of the total population of German firms employed this incentive system in addition to the normal wages. The percentage of companies sharing profits with employees heavily fluctuates according to size and industry affiliation, though. This percentage puts Germany on a mediocre rank, after France (57\%), the UK (40\%) and Sweden (20\%). Van Den Bulcke (1999) identifies factors yielding a less favourable environment with respect to financial participation (which is more general than mere profit-sharing) of German employees: the German tax situation and social security, the complex legislation and the lack of a share ownership culture and tradition.

We constructed our database using various waves of the so-called IAB panel. Since 1993 (1996 for East Germany) the Institute for Employment Research (Institut für Arbeitsmarkt- und Berufsforschung: IAB) yearly surveys a panel of about 16,000 German companies. Based on size and industry affiliation, the sample of surveyed companies is randomly drawn from the employment statistics register of the German Federal Employment Agency (Bundesagentur für Arbeit). Because companies drop out due to non-response or market exit and new companies are continuously established, new companies are added to the sample every year, which results in an unbalanced panel structure. The survey gathers general company information on its establishment, turnover, staffing, investments, etc. but also leaves room for very specific questions, e.g. on public funding, innovation, technical equipment, etc. which are covered on an irregular basis, though.

Our key issue of interest is whether or not companies allow their employees to share in the profit. This information is reflected by the dummy variable PROF. In 2000 , about $10 \%$ of the companies in the total IAB-sample used profit-sharing in addition to a fixed wage to remunerate their employees. In 2005 about $16 \%$ of the companies in the sample employed a system of profit-sharing ${ }^{3}$. Based on the theoretical arguments presented above, we advance the hypothesis that profit-sharing exerts a positive impact on the innovative capabilities of a company. To test our hypotheses, we select all companies from the IAB-sample which introduced profit-sharing between 2000 and 2005 and compare them to a control group of companies which indicated that they did not employ profit-sharing in their remuneration system, neither in 2000 nor in 2005 . We eliminate all the differences in exogenous variables to counter the selectivity issue, employing the matching method. The selected sample of twin companies is then further analysed in a conditional difference-in-differences framework. This

\footnotetext{
${ }^{3}$ Pendleton et al. (2005) report a percentage of $18 \%$ for Germany. However, their study differs in many respects from the data available in the IAB-panel, e.g. in sampling, unit of observation, definition of the incentive schemes, etc. Therefore, the numbers are not comparable. Bellman and Möller (2006) extrapolate data on profit-sharing from the IAB-panel to estimate the share of companies with profit-sharing in the total population of German companies, which is then estimated at about $9 \%$.
} 
will enable us to evaluate the impact of the introduction of a profit-sharing system on a company's innovativeness.

The outcome to be evaluated is twofold: we test whether profit-sharing fosters process and/or product innovation. In the first CDiD variation we proceed as follows. First, we evaluate the company's innovative strength with respect to technological capabilities. TECH measures the condition of a company's technical equipment on a five-point Likert scale, going from fully up-to-date (score $=4$ ) to fully outdated (score $=0$ ). As the IAB-survey does not provide any explicit information on the process innovation capabilities of a company, we believe that this variable is a good proxy. ADVNAR (ADV = advanced; NAR = narrow $)$ and ADV indicate whether the company's technical equipment is fully up-to-date (TECH $=4$ and $\mathrm{TECH}=4$ or 3 , respectively). As TECH is measured in the 2005 and 2000 waves of the IABpanel, we use dynamic variables, reflecting the evolution of the condition of the technical equipment. The first dynamic variable is TECHch, measuring the difference in the condition of the technological equipment between 2005 and 2000 (= TECH05 - TECH00). However, we deliberate about the trade off between the econometric inaccurateness of using the difference in an index value on the one hand and the full use of the available information on the other hand. That is why we additionally include dummy variables reflecting the evolution of the company's technological equipment. We compute a variable indicating whether the company improved its technological strength and became a highly advanced technology user $($ ADVNARch $=1$ if TECH00 $\leq 3$ and TECH05 = 4). We expect all process innovation measures to be affected in a significantly positive way by the introduction of a profit-sharing system.

Second, product innovation is evaluated. This information was taken from the 2004 wave of the IAB panel, as product innovation was not covered in the 2005 wave. We assume that the innovative capability of 2004 is a good approximation for the innovativeness in 2005. INPDT indicates whether the company improved or further developed a product which was already comprised in the company's portfolio, within the two preceding years. NEWFRM measures whether the company adopted a product which was new to the firm, within the two preceding years. NEWFRMint measures the share of these new-to-the-firm products in the turnover. NEWMKT measures whether the company adopted a product which was new to the market, within the two preceding years. Parallel to the measures of new-to-the-firm products, NEWMKTint measures the share of new-to-the-market products in the turnover. INNO equals 1 when at least one of the variables INPDT, NEWFRM or NEWMKT is 1 and hence labels 
companies as innovative or non-innovative in a very broad sense. INNONAR is computed similarly, but narrows down the definition of innovativeness, as only NEWFRM and NEWMKT are included. As information on product innovations was also covered in the 2001 wave, we can again include dynamic product innovation variables, computed as the difference between 2004 and 2001: INPDTch (INPDT04-INPDT01), NEWFRMch (NEWFRM04NEWFRM01), NEWMKTch (NEWMKT04-NEWMKT01), INNOch (INNO04-INNO01) and INNONARch (INNONAR04-INNONAR01). To recapitulate our evaluation set-up in this first CDiD variation, the static variables measure the outcome in period $t_{1}$, while the dynamic variables measure the evolution of the outcome between the periods $t_{0}$ and $t_{1}$. As argued in section 2, we expect to find indications that profit-sharing affects a company's product innovation capabilities, in addition to the effect on the technical equipment. The impact on improvements or the introduction of new-to-the-firm products is expected to be stronger than the impact on the development of totally new (new-to-the-market) products.

We use several control variables which may affect both the probability to employ a profit-sharing remuneration system in addition to a fixed wage and innovative capability of a company, respectively. To avoid endogeneity we measure the value of these covariates in 2000. Including the number of employees (EMP) allows controlling for size effects, which are empirically often found to explain innovativeness (see e.g. Veugelers and Cassiman, 1999). Moreover, size may be related to the company’s choice for a specific incentive scheme. For example, as smaller firms may be better aware of employees' individual performance, they may opt for other financial rewards than a profit-sharing scheme. The logarithmic transformation (lnEMP) is used to smooth this variable. In addition, we removed the 1 and 99 percentile of EMP, to control for extreme size outliers in the dataset. Next, we introduce a number of control variables related to the organizational structure of the firm: the ratio of qualified employees (QUAL) and dummies indicating a shift in responsibilities (SHIFT), the introduction of team work (TEAM) and independent work groups (INDEP) as well as positive investments in ICT infrastructure (ICT) reflect how a company responds to requirements of its environment. Complex and interdependent workflows imply more difficulties in measuring individual output. Moreover, information asymmetries and monitoring problems may be more pronounced. Also a range of variables characterizing how the company interacts with its direct stakeholders is important. First, a high level of trust between employees and managers facilitates consultation and fine-tunes cooperation engagements. The presence of a works council (COUNCIL) is a good proxy for this relationship. Second, the relationship between 
the company and the unions may be important. As we will explain in the following paragraph, Germany is a special case and the works council tends to substitute for the strength of the union, so the variable COUNCIL also reflects the union's power to some extent. In addition, we include a dummy variable (CAO) indicating whether a collective labour agreement is in place. Limited liability may foster the introduction of profit-sharing; LTD has value 1 for joint stock companies (AG) and non-public limited liability companies $(\mathrm{GmbH})$. Last, some final company characteristics are added. After1990 is a dummy indicating whether the company was established after 1990, as profit-sharing and age may interact. Also, firms located in East Germany $(\mathrm{EAST}=1)$ may be less likely to introduce profit-sharing (Möller, 2002 as well as Bellman and Möller, 2006). Finally, industry affiliation may matter. We limit our sample to manufacturing firms, excluding agriculture, mining and construction and include 15 industry dummies (BR) in the analysis.

Our total sample consists of 1348 companies, of which 206 firms are treated (profitsharing). The first empirical step is the selection of a non-profit-sharing twin company for each profit-sharing firm. To this end, a propensity score is estimated in a probit model, using the whole dataset and the control variables introduced above. The summary statistics of these variables (in period $t_{0}$ ) as well as the outcome variables (in period $t_{1}$ or the change (ch) between the two periods $t_{0}$ and $t_{1}$ ) are presented in Table 1 . We also report the p-value statistics of two-sided t-tests, indicating the differences between the profit-sharing firms and the potential control group of all non-profit-sharing firms. In the database we constructed, companies introducing profit-sharing are typically the larger firms (lnEMP***). The work environment seems to be more complex in profit-sharing firms: the share of qualified employees (QUAL***) is higher and the firms are more likely to have introduced a shift in responsibilities (SHIFT***), team work organisation $\left(\mathrm{TEAM}^{* * *}\right)$ or independent work groups (INDEP***). Moreover, the introduction of profit-sharing is positively correlated with investments in the ICT infrastructure (ICT***). Furthermore, profit-sharing firms tend to have a higher level of trust between employees and managers, as they are more likely to have a works council (COUNCIL***). Also the union is more powerful $\left(\mathrm{CAO}^{* * *}\right)$ when the system of profit-sharing is employed. The ownership structure (LTD*** and EAST***) as well as industry affiliation (not reported here) are relevant, too. The age of the company does not seem to matter. 
Table 1: Summary statistics before the matching

\begin{tabular}{|c|c|c|c|c|c|c|}
\hline \multirow[t]{2}{*}{ Variable } & \multirow{2}{*}{ period } & \multicolumn{2}{|c|}{ Profit-sharing firms } & \multicolumn{2}{|c|}{ Potential control group } & \multirow{2}{*}{$\begin{array}{c}\text { p-value } \\
\text { two- } \\
\text { sided t-test }\end{array}$} \\
\hline & & Mean & Std. Err. & Mean & Std. Err. & \\
\hline \multicolumn{7}{|c|}{ OUTCOME VARIABLES } \\
\hline \multicolumn{7}{|c|}{ Process innovation } \\
\hline TECH & $t_{1}$ & 2.8398 & 0.0528 & 2.6445 & 0.0227 & 0.0008 \\
\hline ADVNAR & $t_{1}$ & 0.1845 & 0.0271 & 0.1200 & 0.0096 & 0.0257 \\
\hline ADV & $\mathrm{t}_{1}$ & 0.6893 & 0.0323 & 0.5814 & 0.0146 & 0.0026 \\
\hline TECHch & $\mathrm{t}_{1-} \mathrm{t}_{0}$ & 0.0390 & 0.0488 & 0.1060 & 0.0207 & 0.2081 \\
\hline ADVNARch & $t_{1-} t_{0}$ & 0.1122 & 0.0221 & 0.0630 & 0.0072 & 0.0354 \\
\hline \multicolumn{7}{|l|}{ Product innovation } \\
\hline INPDT & $\mathrm{t}_{1}$ & 0.7805 & 0.0290 & 0.4416 & 0.0147 & 0.0000 \\
\hline NEWFRM & $t_{1}$ & 0.3140 & 0.0323 & 0.2051 & 0.0120 & 0.0018 \\
\hline NEWFRMint & $t_{1}$ & 2.6439 & 0.4835 & 1.7008 & 0.1524 & 0.0640 \\
\hline NEWMKT & $\mathrm{t}_{1}$ & 0.1546 & 0.0252 & 0.0867 & 0.0083 & 0.0111 \\
\hline NEWMKTint & $t_{1}$ & 1.1520 & 0.4682 & 0.7489 & 0.1457 & 0.4119 \\
\hline INNO & $\mathrm{t}_{1}$ & 0.7971 & 0.0280 & 0.4939 & 0.0148 & 0.0000 \\
\hline INNONAR & $\mathrm{t}_{1}$ & 0.3865 & 0.0339 & 0.2546 & 0.0129 & 0.0003 \\
\hline INPDTch & $t_{1-} t_{0}$ & 0.0000 & 0.0318 & -0.0388 & 0.0156 & 0.2743 \\
\hline NEWFRMch & $t_{1-} t_{0}$ & -0.0531 & 0.0412 & -0.0616 & 0.0153 & 0.8481 \\
\hline NEWMKTch & $\mathrm{t}_{1-} \mathrm{t}_{0}$ & -0.0386 & 0.0355 & -0.0229 & 0.0119 & 0.6728 \\
\hline INNOch & $t_{1-} t_{0}$ & 0.0000 & 0.0306 & -0.0446 & 0.0155 & 0.1947 \\
\hline INNONARch & $\mathrm{t}_{1-} \mathrm{t}_{0}$ & -0.0483 & 0.0410 & -0.0719 & 0.0158 & 0.5920 \\
\hline \multicolumn{7}{|c|}{ CONTROL VARIABLES } \\
\hline $\operatorname{lnEMP}$ & $\mathrm{t}_{0}$ & 4.7344 & 0.1109 & 3.2784 & 0.0482 & 0.0000 \\
\hline QUAL & $\mathrm{t}_{0}$ & 0.3149 & 0.0176 & 0.1936 & 0.0065 & 0.0000 \\
\hline SHIFT & $\mathrm{t}_{0}$ & 0.2754 & 0.0311 & 0.1598 & 0.0108 & 0.0005 \\
\hline TEAM & $\mathrm{t}_{0}$ & 0.2367 & 0.0296 & 0.1039 & 0.0090 & 0.0000 \\
\hline INDEP & $\mathrm{t}_{0}$ & 0.1353 & 0.0238 & 0.0550 & 0.0067 & 0.0014 \\
\hline ICT & $\mathrm{t}_{0}$ & 0.8213 & 0.0267 & 0.5677 & 0.0146 & 0.0000 \\
\hline COUNCIL & $\mathrm{t}_{0}$ & 0.7053 & 0.0318 & 0.3031 & 0.0136 & 0.0000 \\
\hline $\mathrm{CAO}$ & $\mathrm{t}_{0}$ & 0.6329 & 0.0336 & 0.4655 & 0.0147 & 0.0000 \\
\hline LTD & $\mathrm{t}_{0}$ & 0.8309 & 0.0261 & 0.5991 & 0.0145 & 0.0000 \\
\hline AFTER1990 & & 0.3865 & 0.0339 & 0.4227 & 0.0146 & 0.3274 \\
\hline EAST & & 0.5990 & 0.0341 & 0.4297 & 0.0146 & 0.0000 \\
\hline Number of obs.: & & \multicolumn{2}{|c|}{206} & \multicolumn{2}{|c|}{1142} & \\
\hline
\end{tabular}

A large body of literature addresses the correlation between a strong union presence on the one hand and R\&D and innovative activity on the other hand. This is highly relevant in the current paper, as the presence of a strong union may be correlated with our treatment as well as outcome variables. Menezes-Filho and Van Reenen (2003) survey the literature in this domain and conclude that North American studies consistently reveal a strongly negative correlation, while European studies cannot substantiate any significant impact of the union on R\&D and innovation. The studies investigating this issue in Germany are Addison and Wagner (1994), Schnabel and Wagner (1992a and b, 1994) as well as Fitzroy and Kraft (1990). Schnabel and Wagner (1992b) ascribe the neutral relationship to the more cooperative nature of industrial relations in Germany.

The relevant labour institutions on the plant and firm level are the unions and also the works councils (see the Works Constitution Act ${ }^{4}$ ). Addison et al. (1996) point out that the German situation is highly specific, because the workplace representation occurs rather

\footnotetext{
${ }^{4}$ This Works Constitution Act (Betriebsverfassungsgesetz) was issued in 1972.
} 
through the mechanism of the works council than through the union. As the ties between the union and the works council are very close, they suggest that the works council substitutes for the union institution in the German case. So, we feel confident here to assume that the presence of a works council and the union's bargaining power (variables COUNCIL and CAO) have no impact on the innovative activity in German firms. Adversely, these variables are expected to have an impact on the propensity to introduce profit-sharing, i.e. our treatment variable.

After the matching, the evolution in the outcome variables (both static and dynamic) is evaluated for the subsample of matched pairs. This approach eliminates a considerable share of observed as well as unobserved heterogeneity in the treated and non-treated firms in the population and mitigates the potential selectivity bias. The first CDiD variation conducts twosided t-tests to compare the means of the two groups after the matching. In the second CDiD approach, we also start off with the results obtained from the matching analysis, but then regress the outcome variables in a common DiD set-up on the treatment and exogenous variables. In this way, we also control for the change over time in the control variables. The variables which will be used to assess companies' innovative capabilities in the second CDiD variation are similar to the variables described above. Process innovation will be assessed with the variables TECH, ADVNAR and ADV. Product innovation will be evaluated on the variables INPDT, NEWFRM and NEWMKT. So, the difference in innovative capabilities is regressed on the treatment variable (PROF $=$ introduction of profit-sharing between $t_{0}$ and $t_{1}$ ), the evolution of the exogenous characteristics (lnEMP, QUAL, SHIFT, TEAM, INDEP, ICT, COUNCIL, CAO and LTD) as well as dummy variable YEAR, indicating the year of the observation. By definition, this dataset consists of a balanced panel, with information on 404 companies (resulting in 808 observations, as two periods of data are available).

\section{Estimates}

The potential presence of selectivity in this evaluation exercise was introduced in the methodological section. Because of this potential endogeneity, a simple comparison of the outcome variables between companies with and without profit-sharing (as presented in Table 1) does not provide an adequate answer in this evaluation research; the introduction of profitsharing may be induced by innovativeness. We observe significant differences in the innovative strength between profit-sharing companies and the potential control group. However, the control variables differ significantly as well and these differences may also 
explain differences in innovativeness. We address this potential selection bias empirically starting from nearest neighbour propensity score matching with replacement. Then we take two variations on the CDiD approach to assess the evolution of the outcome variables over time. This technique ensures that both observable and unobservable differences between treated and non-treated companies are taken into account, as well as any macro-economic change over time. We believe that the data at hand is sufficiently rich and that the matching procedure significantly curtails the selection bias. As a result, any potentially remaining difference in the outcome variables can be attributed to the introduction of profit-sharing.

To select a non-profit-sharing twin company for each profit-sharing company, we first estimate the propensity score, which reflects the probability that a company remunerates its employees with a system of profit-sharing in addition to a fixed wage. This model is presented in Table 2. In the probit model, size (lnEMP**), the share of qualified employees $\left(\mathrm{QUAL}^{* * *}\right)$ and the presence of a works council (COUNCIL***) are significant. Also industry affiliation $\left(\mathrm{BR}^{* *}\right)$ matters. These estimates confirm expectations formulated in the section on selectivity. Smaller companies rather opt for other incentive schemes than profitsharing. Companies employing large shares of qualified people are more likely to adopt profit-sharing. The presence of a works council, reflecting a high level of trust between company owners and employees as well as the bargaining power of the union, also create a favourable setting for a profit-sharing incentive scheme.

Table 2: Propensity to employ profit-sharing

\begin{tabular}{|c|c|c|c|c|c|c|}
\hline & \multicolumn{3}{|c|}{ Probit estimates } & \multicolumn{3}{|c|}{ Marginal effects } \\
\hline & Coef & & Std. Err. & $d y / d x$ & & Std. Err. \\
\hline $\operatorname{lnEMP}$ & 0.1059 & ** & 0.0461 & 0.0196 & $* *$ & 0.0085 \\
\hline QUAL & 0.6677 & $* * *$ & 0.1999 & 0.1235 & $* * *$ & 0.0369 \\
\hline $\mathrm{SHIFT}^{\circ}$ & 0.0403 & & 0.1195 & 0.0076 & & 0.0228 \\
\hline TEAM $^{\circ}$ & 0.0721 & & 0.1321 & 0.0138 & & 0.0261 \\
\hline $\mathrm{INDEP}^{\circ}$ & 0.1656 & & 0.1647 & 0.0334 & & 0.0361 \\
\hline $\mathrm{ICT}^{\circ}$ & 0.1545 & & 0.117 & 0.0280 & & 0.0207 \\
\hline COUNCIL $^{\circ}$ & 0.5412 & $* * *$ & 0.1413 & 0.1098 & $* * *$ & 0.0312 \\
\hline $\mathrm{CAO}^{\circ}$ & -0.0917 & & 0.1134 & -0.0170 & & 0.0209 \\
\hline LTD $^{\circ}$ & 0.1933 & & 0.1191 & 0.0346 & & 0.0205 \\
\hline AFTER $1990^{\circ}$ & 0.1762 & & 0.1252 & 0.0332 & & 0.0239 \\
\hline EAST $^{\circ}$ & 0.1507 & & 0.1266 & 0.0281 & & 0.0238 \\
\hline constant & -2.4041 & $* * *$ & 0.2332 & & & \\
\hline $\mathrm{BR}$ & $\chi^{2}(1$ & 4) $=28$ & & & & \\
\hline Log-Likelihood & & -475 & & & & \\
\hline Pseudo $\mathrm{R}^{2}$ & & 0.179 & & & & \\
\hline \# obs. & & 1352 & & & & \\
\hline
\end{tabular}


The probit model provides estimated propensity scores and enables us to select ${ }^{5}$ similar companies. After the matching process, any difference in the control variables is eliminated and the remaining differences in outcome variables can be attributed to the introduction of a profit-sharing system. In the first analysis, we evaluate how the outcome has evolved over time in the profit-sharing firms and their selected twin partners, respectively. Table 3 shows the difference in outcome variables, which reflect innovative capabilities. Profit-sharing companies are more likely to have a fully up-to-date technical equipment after the introduction of profit-sharing (TECHch**). Also in the same time period, profit-sharing companies are more innovative than their non-profit-sharing twin companies $\left(\mathrm{TECH}^{* *}\right)$. They are significantly more eager to use advanced technologies (ADV** and ADVNAR**) and companies introducing profit-sharing have become more advanced technology users (ADVNARch**). Our hypothesis on the impact of profit-sharing on a company's technological strength is confirmed.

Also the outcome variables measuring product innovation significantly differ after the matching. We notice that profit-sharing companies are more likely to have improved a product in the company's existing portfolio (INPDT***) or introduced a new-to-the-firm product (NEWFRM***). Also, profit-sharing enables companies to realize a higher share of their turnover based on new-to-the-firm products (NEWFRMint***). The general measures on product innovativeness show that they are more innovative in comparison with companies that did not introduce profit-sharing (INNO** and INNONAR**). However, as expected as well, this increased performance in product innovation is limited to the improvement of existing products and the introduction of products which are new to the company, but not to the market (NEWMKT and NEWMKTint do not differ significantly between the two matched samples). As profit-sharing increases employee involvement in the innovation process, they are more likely to disclose relevant and valuable information. This information is important, but the knowledge captured in the company's human resources, is relatively 'straightforward'. The information does not contribute to the development of radical innovations, or, as measured here, innovations which are new to the market. Another expectation was that the impact of profit-sharing is larger with respect to process than product innovation. The dynamic variables reflecting the change in companies' product innovation capabilities are not significantly different after the matching (INPDTch, NEWFRMch, NEWMKTch, INNOch and INNONARch). This result seems to indicate that the companies which introduced profit-

\footnotetext{
${ }^{5}$ The selection process is based on a minimization of the Mahalanobis distance between companies. We match with replacement, to optimize the matching quality.
} 
sharing already were more innovative before the introduction. Hence, companies which have higher product innovative capabilities are more likely to employ better remuneration systems. We will return to this issue when we discuss the results of our second approach.

Table 3: Outcome variables matched samples

\begin{tabular}{|c|c|c|c|c|c|c|}
\hline & \multicolumn{2}{|c|}{ Profit-sharing firms } & \multicolumn{2}{|c|}{ Selected control group } & \multirow{2}{*}{\multicolumn{2}{|c|}{$\boldsymbol{\theta}$}} \\
\hline & Mean & Std. Err. & Mean & Std. Err. & & \\
\hline \multicolumn{7}{|l|}{ Process innovation } \\
\hline TECH & 2.8439 & 0.0529 & 2.6634 & 0.0503 & 0.1805 & ** \\
\hline ADVNAR & 0.1854 & 0.0272 & 0.1073 & 0.0217 & 0.0781 & $* *$ \\
\hline $\mathrm{ADV}$ & 0.5854 & 0.0345 & 0.6927 & 0.0323 & 0.1073 & $* *$ \\
\hline TECHch & -0.0390 & 0.0488 & -0.1902 & 0.0512 & 0.1512 & ** \\
\hline ADVNARch & 0.1122 & 0.0221 & 0.0537 & 0.0158 & 0.0585 & ** \\
\hline \multicolumn{7}{|l|}{ Product innovation } \\
\hline INPDT & 0.7833 & 0.0290 & 0.6517 & 0.0337 & 0.1315 & $* * *$ \\
\hline NEWFRM & 0.3122 & 0.0324 & 0.1832 & 0.0273 & 0.1290 & $* * *$ \\
\hline NEWFRMint & 2.6650 & 0.4880 & 1.2165 & 0.2661 & 1.4485 & $* * *$ \\
\hline NEWMKT & 0.1512 & 0.0251 & 0.1188 & 0.0228 & 0.0324 & \\
\hline NEWMKTint & 1.1485 & 0.4727 & 1.3366 & 0.5467 & 0.1881 & \\
\hline INNO & 0.8000 & 0.0280 & 0.7129 & 0.0319 & 0.0871 & ** \\
\hline INNONAR & 0.3854 & 0.0341 & 0.2772 & 0.0316 & 0.1081 & $* *$ \\
\hline INPDTch & 0.0322 & 0.4571 & 0.0371 & 0.5177 & 0.0491 & \\
\hline NEWFRMch & -0.0537 & 0.0416 & -0.0896 & 0.0406 & -0.0359 & \\
\hline NEWMKTch & -0.0439 & 0.0355 & -0.0297 & 0.0336 & 0.0142 & \\
\hline INNOch & 0.0000 & 0.0309 & 0.0347 & 0.0347 & 0.0347 & \\
\hline INNONARch & -0.0488 & 0.0414 & -0.0792 & 0.0429 & -0.0304 & \\
\hline \# obs. & \multicolumn{2}{|c|}{205} & \multicolumn{2}{|c|}{205} & & \\
\hline \multicolumn{7}{|c|}{$\begin{array}{l}\text { Note: the control variables (lnEMP, QUAL, SHIFT, TEAM, INDEP, ICT, COUNCIL, CAO, LTD, AFTER1990, } \\
\text { EAST and BR) as well as the propensity score are not significantly different after the matching and therefore not } \\
\text { reported here. The common support restriction was imposed, but no treated firms had to be removed; some } \\
\text { observations were lost because of missing values, though. } * * *(* *, *) \text { indicate a significance level of } 1 \%(5,10 \%) \text { of } \\
\text { the t-tests on mean equality between the sample of funded firms and the selected control group. } \theta \text { is the average } \\
\text { treatment effect of profit-sharing. }\end{array}$} \\
\hline
\end{tabular}

To complete the first CDiD variation, we now conduct a second variation: in the matched panel, constructed with the matching procedure, we regress the outcome variables on our treatment variable (PROF), a year dummy (YEAR) and the exogenous time-varying characteristics (InEMP, QUAL, SHIFT, TEAM, INDEP, ICT, COUNCIL, CAO, LTD). In this set-up, both observed and unobserved differences in exogenous characteristics are explicitly controlled for, as well as different reactions to macro-economic changes over time from firms which do and do not share profits with their employees. The reader is reminded here that the probit models only allow a qualitative evaluation, as only the sign and significance of the treatment effect can be determined. The results are presented in Table 4 . Compared to the first approach, the conclusions are less strong, but by and large still hold. The panel regression on the variable TECH is significant in the random effects model, but not in the fixed effects model, which is most appropriate in treatment analysis according to Wooldridge (2002) and the Hausman test. The sign of the coefficient is negative, which is in line with our expectations. The estimates for the dummy variables ADVNAR and ADV are 
significantly positive and confirm our previous findings. With respect to process innovations, we therefore conclude that profit-sharing firms seem to hold a technologically stronger position than firms without profit-sharing. Turning to the measures for product innovation, a positive effect can be found on the likelihood to introduce new-to-the-firm products $\left(\mathrm{NEWFRM}^{* * *}\right)$, which are however not new-to-the-market (NEWMKT). The estimate for INPDT is not significant (the p-value of the estimated coefficient is 0.120). The first CDiD variation (see Table 3) did not provide evidence to support our hypothesis that companies improve their product innovative capabilities after the introduction of profit-sharing; it seemed that mainly the better performing companies introduce profit-sharing, explaining the insignificance of changes in product innovativeness over time. However, our estimate for NEWFRM*** now suggests that profit-sharing firms outperform non-profit-sharing firms, but that profit-sharing firms also enhance their performance with respect to product innovation once they introduce this remuneration scheme. To conclude, our analyses provide substantial support in favour of the hypotheses we built based on theoretical arguments. We conclude that profit-sharing enhances companies' innovative capabilities, both on the level of product and process innovations.

Table 4: CDiD regressions

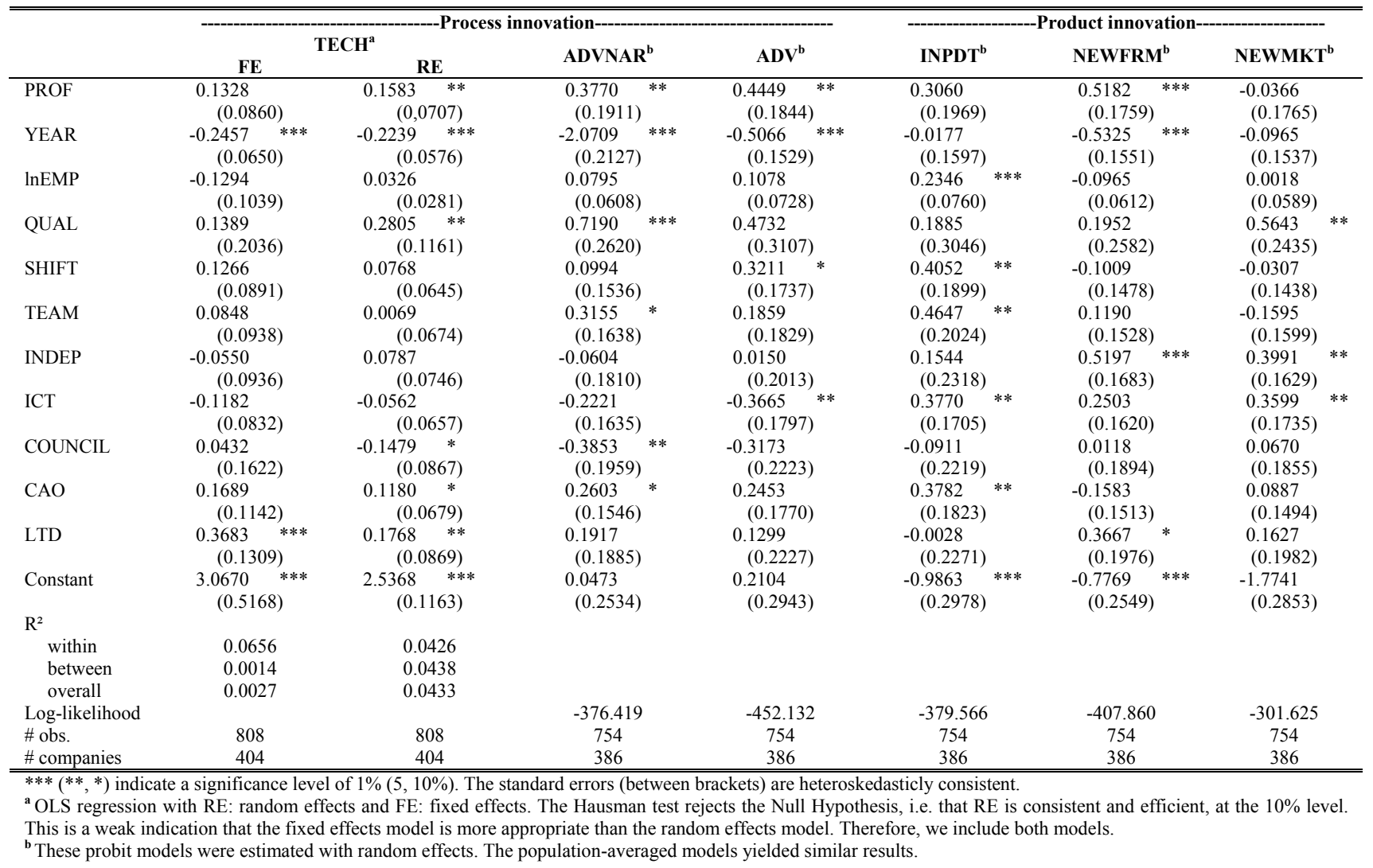




\section{Conclusion}

We empirically investigated the impact of profit-sharing on the innovative capabilities of German manufacturing companies. Since the introduction of a profit-sharing system may be endogenous, we employ two variations of the CDiD approach. Once the potential selection bias is eliminated, companies with and without a profit-sharing system still differ significantly in their innovativeness. Profit-sharing companies outperform non-profit-sharing companies on both process and product innovativeness. The introduction of profit-sharing increases the strength of a company's technological equipment.

In Bellman and Möller (2006) two profiles of companies introducing profit-sharing emerge. On the one hand profit-sharing companies are the larger companies with a complex working environment, introducing profit-sharing to motivate the workforce. On the other hand also small and young, technology-oriented firms introduce profit-sharing as they do not have substantial resources to attract and keep highly qualified employees; the profit premium is treated as a bonus to the regular pay slip. The firms in our sample, introducing profit-sharing, are mainly the larger firms, with a more complex work environment, a high level of trust between employees and managers and a powerful union. The ownership structure as well as industry affiliation is relevant, too. The age of the company does not seem to matter. Therefore, the firms in our sample seem to belong mainly to the first profile. Hence, the impact of profit-sharing on innovativeness may be different in smaller high-tech firms.

The results presented in this paper establish valid proof supporting the hypotheses developed on the impact of profit-sharing on a company's innovative activity. However, as new survey waves will become available and existing datasets may be extended, robustness checks, e.g. with different specifications of the moment when the economic return becomes apparent, different measures of innovativeness, etc. will provide valuable additional insights into this domain. An interesting point of view was advanced by Lerner and Wulf (2007), who link different incentive schemes to reward $R \& D$ managers to patenting activity. Also the size of the profit premium, instead of mere stochastic information on the application of this remuneration scheme, could yield an interesting path for further research, as the impact of profit-sharing may be heterogeneous in size.

Although our results suggest that profit-sharing adds to companies' innovative capacity, the share of German companies actually employing this system is rather limited in comparison with other countries (especially France and the UK). Research on the obstacles 
hampering German employers to let employees share in the profit indicates an unfavourable taxation system, the complex legislation system as well as a bad fit with the cultural background as key problems (Van Den Bulcke, 1999). Therefore, German policy makers may consider designing a more profit-sharing friendly environment for German companies. Besides the potential positive productivity and employment gains, also the national innovative capacity may benefit from this remuneration system.

\section{Acknowledgements}

The authors are grateful to the Institute for Employment Research (IAB) for providing the data with remote access and to Julia Lang for transmitting endless program lists. This paper was initiated during a short research visit of Kris Aerts to the Technical University of Dortmund. She is grateful for the university's hospitality. Moreover, the comments of Dirk Czarnitzki, Koen Debackere, Pierre Mohnen and Reinhilde Veugelers are highly appreciated.

\section{References}

Addison, J.T., Schnabel, C., Wagner, J., 1996. German works councils, profits, and innovation, Kyklos 49(4), 555-582.

Addison, J.T., Wagner, J. 1994. UK Unionism and Innovative Activity: Some Cautionary Remarks on the Basis of a Simple Cross-Country Test, British Journal of Industrial Relations 32(1), 85-98.

Aerts, K., Schmidt, T., 2008. Two for the price of one? On additionality effects of R\&D subsidies: A comparison between Flanders and Germany, Research Policy 37(5), 806-822.

Albrecht, J., van den Berg, G.J., Vroman, S., 2005. The Knowledge Lift: The Swedish Adult Education Program That Aimed to Eliminate Low Worker Skill Levels, IZA Discussion Paper 1503, Institute for the Study of Labour (IZA), Bonn.

Bellman, L., Möller, I., 2006. Die Betriebe in Deutschland haben Nachholbedarf, Institut für Arbeitsmarkt- und Berufsforschung (IAB) Kurzbericht 13 / 5.9.2006, Bundesagentur für Arbeit, Nürnberg.

Bergemann, A., Fitzenberger, B., Speckesser, S., 2004. Evaluating the Dynamic Employment Effects of Training Programs in East Germany Using Conditional Difference-in- 
Differences, ZEW Discussion Paper 04-41, Centre for European Economic Research (ZEW), Mannheim.

Bhargava, S., Jenkinson, T., 1995. Explicit versus Implicit Profit Sharing and the Determination of Wages, Labour 9(1), 73-95.

Blundell, R., Costa Dias, M., 2000. Evaluation Methods for Non-Experimental Data, Fiscal Studies 21(4), 427-468.

Commission of the European Communities, 1991. PEPPER I Report: Promotion of employee participation in profits and enterprise results, supplement 3/91, Brussels.

Commission of the European Communities, 1996. PEPPER II Report: Promotion of employee participation in profits and enterprise results, $\operatorname{COM}(96) 697$, Brussels.

Coombs, G., Gomez-Mejia, L.R., 1991. Cross-functional compensation strategies in high technology firms, Compensation and Benefits Review 23(5), 40-48.

Dasgupta, P., Maskin, E., 1987. The Simple Economics of Research Portfolios, The Economic Journal 97(387), 581-595.

Doucouliagos, C., 1995. Worker Participation and Productivity in Labour-Managed and Participatory Capitalist Firms: A Meta-Analysis, Industrial and Labour Relations Review 49(1), 58-77.

Eichler, M., Lechner, M., 2002. An Evaluation of Public Employment Programmes in the East German State of Sachsen-Anhalt, Labour Economics 9(2), 143-186.

FitzRoy, F., Kraft, K., 1987. Cooperation, Productivity and Profit Sharing, Quarterly Journal of Economics 102(1), 23-35.

Fitzroy, F., Kraft, K., 1990. Innovation, Rent-Sharing and the Organization of Labour in the Federal Republic of Germany, Small Business Economics 2(4) 95-103.

FitzRoy, F., Kraft, K., 1995. On the Choice of Incentives in the Firm, Journal of Economic Behaviour and Organization 26(1), 145-160.

Halaby, C.N., 2004. Panel models in sociological research: Theory into practice, Annual Review of Sociology 30, 507-544.

Heckman, J.J., Ichimura, H., Todd, P., 1997. Matching as an Econometric Evaluation Estimator: Evidence from evaluating a job training programma, Review of Economic Studies 64(4), 605-654. 
Kluve, J., Lehmann, H., Schmidt, C.M., 1999. Active Labour Market Policies in Poland: Human Capital Enhancement, Stigmatization or Benefit Churning? Journal of Comparative Economics 27(1), 61-89.

Kraft, K., Ugarković, M., 2007. Profit-Sharing: Supplement or Substitute?, mimeo University of Dortmund, Dortmund.

Lechner, M., 1998. Training the East German labour force: microeconometric evaluations of continuous vocational training after unification, Heidelberg.

Lerner, J., Wulf, J., 2007. Innovation and incentives: evidence from corporate R\&D, The Review of Economics and Statistics 89(4), 634-644.

Lowitzsch, J., 2006. Commission of the European Communities, 1996, PEPPER III Report: Promotion of employee participation in profits and enterprise results in the New Member and Candidate Countries of the European Union.

Mansfield, E., 1985. How rapidly does new industrial technology leak out?, The Journal of Industrial Economics 34(2), 217-223.

Menezes-Filho, N., Van Reenen, J., 2003. Unions and innovation: a survey of the theory and empirical evidence, CEPR Discussion Paper 3792, London.

Möller, I., 2002. Produktivitätswirkung von Mitarbeiterbeteiligung: Der Einfluss von unbeobachteter Heterogenität. MittAB 1, 123-132.

Pendleton, A., Poutsma, E., van Ommeren, J., Brewster, Ch., 2005. Employee share ownership and profit-sharing in the European Union, The European Foundation for the Improvement of Living and Working Conditions, Dublin.

Pérotin, V., Robinson, A., 2002. Employee participation in profit and ownership: A review of the issues and evidence, Leeds University Business School, Leeds.

Poutsma, E., 2001. Recent Trends in Employee Financial Participation in the European Union, Office for the Official Publications of the European Communities, Luxembourg.

Romer, P.M., 1990. Endogenous Technological Change, Journal of Political Economy 98(5), 71-102.

Rosenbaum, P.R., Rubin, D.B., 1983. The Central Role of the Propensity Score in Observational Studies for Causal Effects, Biometrika 70, 41-55. 
Roy, A.D., 1951. Some Thoughts on the Distribution of Earnings, Oxford Economic Papers $3(2), 135-146$.

Rubin, D.B., 1974. Estimating Causal Effects of Treatments in Randomized and NonRandomized Studies, Journal of Educational Psychology 66, 688-701.

Rubin, D.B., 1977. Assignment to Treatment Group on the Basis of Covariate, Journal of Educational Statistics 2, 1-26.

Schaefer, S., 1998. Influence costs, structural inertia, and organizational change, Journal of Economics \& Management Strategy 7(2), 237-263.

Schnabel, C., Wagner, J., 1992a. Unions and Innovative Activity in Germany, Journal of Labour Research 13(8), 393-406.

Schnabel, C., Wagner, J., 1992b. Unions and Innovations: Evidence from Germany, Economics Letters 39, 369--73.

Schnabel, C., Wagner, J., 1994. Industrial Relations and Trade Union effects on Innovation in Germany, Labour 8(3), 489-503.

Schumpeter, J.A., 1942. Capitalism, socialism and democracy. Harper \& Brothers, New York.

Strotmann, H., 2002. Zur Bedeutung materieller Mitarbeiterbeteiligung in BadenWürttemberg - eine empirische Analyse mit dem IAB-Betriebspanel, IAW report, Institut für angewandte Wirtschaftsforschung (IAW), Tübingen.

Van Den Bulcke, F., 1999. A company perspective on financial participation in the European Union: Objectives and obstacles, Report, Research Centre for Financial Participation, K.U. Brussel, Brussels.

Veugelers, R., Cassiman, B., 1999. Make or buy in innovation strategies: evidence from Belgian manufacturing firms, Research Policy 28(1), 63-80.

Wadhwani, S., Wall, M., 1990. The effects of profit-sharing on employment, wages, stock returns and productivity: evidence from UK micro-data, Economic Journal 100(399), 1-17.

Weitzman, M.L., 1983. Some Macroeconomic Implications of Alternative Compensation Systems, The Economic Journal 93(372), 763-783.

Wooldridge, J.M., 2002. Econometric analysis of cross section and panel data, Massachusetts Institute of Technology Press, Cambridge/London. 
Zwick, T., 2002. Empirical determinants of employee resistance against innovations, International Journal of Manpower 23(6), 542-552. 